\title{
ИНСТИТУЦИОНАЛЬНЫЕ АСПЕКТЫ ИННОВАЦИОННОГО РАЗВИТИЯ НАЦИОНАЛЬНОЙ ЭКОНОМИКИ В УСЛОВИЯХ ГЛОБАЛИЗАЦИИ
}

\author{
Е. Б. ДОРИНА
}

Аннотация:

В статье рассматриваются актуальные вопросы институционализации национальной экономики Республики Беларусь с учетом глобализационных процессов и инновационного развития. Рассмотрены институциональные аспекты экономических отношений во взаимосвязи с глобализацией мировой экономики и инновационным развитием. Сделаны выводы о том, что институционализация - это замена спонтанного поведения на предсказуемое, которое ожидается, моделируется, регулируется в процессе институционального проектирования. Особую актуальность приобретает формирование концептуальных направлений реализации институциональной стратегии как основы функционирования и инновационного развития национальной экономики.

\section{ВВЕДЕНИЕ}

Циклические процессы, особо остро проявляющие себя в виде кризисов, становятся неотъемлемым элементом развития мировой экономики. Для общества важно, чтобы экономическая динамика служила средством социального и инновационного развития, а не рассматривалась лишь как способность экономических агентов к согласованному действию, партнерству между бизнесом и органами управления.

Экономические кризисы становятся глобальными, поскольку мир глобализован и интегрирован. Причина всех глобальных экономических кризисов лежит в сфере смены технологической парадигмы развития. Кризис является расплатой за инерцию в смене технологической и, как следствие, экономической парадигмы.

Неоклассическая теория оказалась неспособной как к прогнозированию глобальных кризисов, так и к выработке механизмов их предотвращения. Экономическая наука переживает переломный этап своего развития, обусловленный формированием новой институциональной парадигмы, основанной на синтезе научных достижений, междисциплинарном подходе к исследованию постиндустриальной экономики, развивающейся под воздействием как революционных, так и эволюционных инноваций, способной заменить ортодоксальную теорию, обосновывающую экономические проблемы в рамках саморегулирующегося рыночного механизма, в отрыве от решения глобальных вопросов, изучения глубинных и долговременных изменений в обществе и мире в целом.

В экономической литературе недостаточно полно исследованы многие фундаментальные вопросы, связанные с институциональным анализом проблем 
трансформации институтов и их функций через призму категорий «глобализация» и «инновация». Требуют обоснования многие проблемы, обусловленные выявлением и сопоставлением основных тенденций и закономерностей развития институтов в отдельных странах или группах стран в условиях глобализации.

Представляется, что главной задачей экономической науки должны стать исследования, формирующие целостное видение экономических процессов. Важнейшие среди них: институционализация инновационного развития национальной экономики, целенаправленное конструирование и постепенное «выращивание» экономических и социальных институтов, обеспечивающих конкурентоспособность и экономический рост. Поэтому необходимо развивать новые направления исследований, анализирующие изменение экономических институтов в переходный к инновационной экономике период. В этом смысле институционализм можно считать наиболее перспективным направлением современной экономической науки.

Очевидно, что повышенный интерес ученых к институциональной теории и методологии исследования проблем социально-экономического развития обусловлен их существенными возможностями. Институциональный анализ позволяет более глубоко осмыслить инновационные процессы, оценить их сценарий; разработать стратегию научно-технического развития на перспективу; обозначить круг субъектов и объектов институционального воздействия.

Среди ключевых факторов эволюционного обновления общества на первый план представители институциональной теории выдвигают научнотехническую революцию, преобразующую индустриальную структуру общества в постиндустриальную. Источник перемен они видят в развитии науки, техники, в создании принципиально новых технологий. Технологическую трактовку приобретают проблемы экономического роста, экономических кризисов, а также сдвиги в социальной структуре общества. Институционалисты исходят из того, что научно-технический прогресс непосредственно определяет экономическое и социальное развитие общества, является решающим фактором его обновления. Техника, технология, по существу, отождествляется с социальноэкономическими структурами. На принципе технологического детерминизма базируются теории индустриального, постиндустриального, супериндустриального, технотронного, информационного обществ и др.

Д. Белл, Дж. К. Гэлбрейт, О. Тоффлер и другие ученые исследовали современные аспекты методологии технологического детерминизма, информационного и постиндустриального общества. Реализация идеи социального контроля посредством планирования, разработка рекомендаций по преодолению экономической отсталости и нищеты в рамках мирового хозяйства, предложений по практическому решению социальных проблем, а также анализ влияния институтов на динамику развития национальной экономики осуществлены в работах Г. Мюрдаля, Р. Нельсона, Ф. Перру, С. Уинтера.

Теория техноструктуры, конвергенции. Современные аспекты методологии технологического детерминизма, общей концепции социально- 
институционального направления, его целей и задач наиболее ярко и широко представлены в трудах Дж.К. Гэлбрейта, критиковавшего основные постулаты неоклассической теории. По его мнению, традиционная экономическая теория оперирует понятиями и методами, которые относятся не столько к современной, сколько к прошлой экономической системе. Современная экономика состоит, в сущности, из двух подсистем - плановой и рыночной. Первая из них представлена большими корпорациями, вторая - мелким и средним бизнесом.

Объединение людей в крупной корпорации Гэлбрейт назвал техноструктурой, к которой относит тех, кто обладает специальными знаниями, способностями и опытом группового принятия решений. Главная роль в техноструктуре принадлежит ведущим менеджерам, принимающим основные управленческие решения. Анализ и выводы Дж. Гэлбрейта по вопросам структуры и управления корпорацией и планирующей системой опираются на выявление власти техноструктуры и институциональной власти корпораций. Анализирует влияние, которое оказывает техноструктура на поведение индивидов. Дж. Гэлбрейт развил также теорию «конвергенции» социализма и капитализма. Особое внимание Гэлбрейта направлено на разработку системы реформ, которые в состоянии обеспечить решение острых социально-экономических проблем, существенно улучшить положение общества.

П. Друкер анализирует социальную сторону постиндустриальных преобразований и характеризует новое общество как общество знаний, уже не являющееся ни капитализмом, ни социализмом.

Методологическим основанием концепции постиндустриального общества, информационного общества, теории информации являются принцип технологического детерминизма и гуманистический подход к характеру социально-экономических отношений в обществе. Согласно Д. Беллу, постиндустриальное - это общество интеллектуалов, «познающее общество», в котором первостепенное значение придается всестороннему развитию его членов. В нем главную роль начинают играть теоретические знания, поэтому его основной проблемой, по Беллу, являются вопросы организации науки. Трансформация охватывает и формы собственности на средства производства, и социальную структуру общества. Развитие информационного производства, по его мнению, осуществляет переворот как в технике и технологии производства, так и в характере социальных отношений в обществе.

Согласно Д. Беллу, постиндустриальное - это общество интеллектуалов, «познающее общество», в котором первостепенное значение придается всестороннему развитию его членов. В нем главную роль начинают играть теоретические знания, поэтому его основной проблемой, по Беллу, являются вопросы организации науки. Трансформация охватывает и формы собственности на средства производства, и социальную структуру общества. Развитие информационного производства, по его мнению, осуществляет переворот как в технике и технологии производства, так и в характере социальных отношений в обществе. 
В сфере социально-экономических отношений Д. Белл выделяет вертикальные подразделения, включающие четыре функциональных «ситоса» (научный, технологический, культурный и административный) и пять институциональных (экономические предприятия, правительственные конторы, университеты и исследовательские центры, социальные комплексы, военная сфера). В результате у Белла получается, что основные классы индустриального общества с переходом к информационному обществу сами собой растворяются и тем самым формируются различного рода локально-профессиональные группы.

Э. Тоффлер оценивает постиндустриальный этап как компьютерноинформационную цивилизацию третьей волны в истории человеческого развития. Новый образ информационного общества, по его мнению, формируется на следующей основе: коммуникационный спутник - кабельное телевидение персональный компьютер.

Гуманистический подход к анализу и решению проблем системы «человек - экономика - окружающая среда» характерен для К. Флекснера. Каждый человек, отмечает он, должен быть в центре внимания экономического прогресса в отличие от современной позиции, где в центре внимания - экономические затраты. В связи с этим он считает, что необходимо заменить социальный дарвинизм, благоприятствующий тем, кто стремится к власти, на систему, направленную на улучшение условий жизни человека.

Проблема трансформации общества выдвинута на первый план и занимает центральное место в теоретических построениях институционалистов на основе разработки футурологических сценариев, прогнозов развития общества в ближайшем и более отдаленном будущем. Одним из вариантов институциональной интерпретации трансформации общества под влиянием НТР является концепция Р. Хейлбронера. По его мнению, на ранних стадиях развития индустриального общества основным механизмом трансформации и адаптации был рынок. Со второй половины XIX века важнейшим фактором развития экономики становятся наука и техника. В организации социального контроля Р. Хейлбронер возлагает надежды на социальные программы, призванные расширять и укреплять экономическую базу государственного регулирования экономики и повышать его действенность.

Общим методологическим принципом построения национальной инновационной системы является следование идеям Й. Шумпетера о конкуренции на основе инноваций в корпорациях как главном факторе экономической динамики, о роли институционального контекста инновационной деятельности как фактора, прямо влияющего на ее содержание и структуру.

В связи с процессами глобализации необходимо создавать инновационную национальную экономику с новейшими институциональными формами и технологиями функционирования. Переход к новой модели, в том числе в сфере государственного управления требует своего институционального оформления, своих специфических организационно-функциональных и координирующих структур. 
Главной задачей экономической науки должны стать исследования, формирующие целостное видение экономических процессов в условиях глобализации. Важнейшие среди них: институциональные формы инновационного развития национальной экономики и управления. Глобализация усилила информатизацию, базирующуюся на новейших достижениях в области электроники и систем связи. Поэтому необходимо развивать новые направления исследований, анализирующие изменение экономических институтов при переходе к информационному обществу и инновационной экономике.

Не нашли отражения в экономической теории вопросы заимствования и адаптации институтов с учетом уровня зрелости и состояния национальной экономики, изучения условий их перехода к инновационной экономике, разработки эффективного механизма реализации институциональных преобразований как основы модернизации экономики.

Сегодня мировая экономика находится в состоянии перманентной трансформации. Мощнейшим фактором ее развития являются процессы глобализации и стремительная смена современных технологий, что ускорило инновационную динамику экономики развитых стран. Так, информационные технологии в настоящее время обеспечивают не менее трети валового национального продукта США. Наноиндустриализация может стать основой обновления национальной экономики многих стран, повышения экономической устойчивости и роста благосостояния нации, а также исчезновения и появления множества отраслей промышленности. Вместе с тем новейшие разработки в области новых технологий и их влияние на бизнес и экономику означают, что стратегические прогнозы становятся менее точными. Тем не менее, нанотехнологии способны придать развитию глобальной экономики невиданную ранее скорость, которая опасна сама по себе.

Современное состояние мирового хозяйства, стремление к усилению, с одной стороны, интеграционных процессов, а с другой - ориентация стран на сохранение индивидуальных моноэкономических особенностей выдвигают перед экономической наукой задачу более глубокого и всестороннего исследования тенденций развития с учетом процессов глобализации.

\section{РЕЗУЛЬТАТЫ И ИХ ОБСУЖДЕНИЕ}

Существующие трактовки и подходы к глобализации отражают ее сложность, многогранность, внутреннюю и внешнюю противоречивость. С институциональной точки зрения глобализация, с одной стороны - это исторический процесс, эволюционно развивающийся, который обусловил приверженность стран, народов единым ценностям, обычаям и нормам поведения на основе единых культур, с другой - процесс, сопровождающийся растущей взаимозависимостью, разрушением национальных особенностей государств, научнотехническим, инновационным и инвестиционным превосходством транснациональных институтов в управлении мировой экономикой.

Глобализация неоднозначно влияет на внешнеэкономические отношения. В первую очередь нарушается механизм равноправного сотрудничества. Осо- 
бенно негативно данные процессы влияют на страны с транзитивными экономиками. Отсюда стремление таких стран к интеграции и либерализации внешней торговли.

Мировые трансформационные процессы связаны, прежде всего, с глобализацией - объективным процессом превращения экономик отдельных стран из относительно замкнутых систем в элементы единого мирового хозяйства. В основе глобализации лежит международное разделение труда и связанные с ним экономические, политические и другие отношения между государствами, организациями, фирмами, объединяющие национальные экономики и формирующие единый мировой рынок.

В целом доминирующие тенденции в мировой экономике, создающие новую глобальную экономическую реальность, можно классифицировать как:

- переход от индустриальной к инновационной экономике в развитых странах;

- глобализация;

- экономическая и социальная либерализация;

- нарастание глобальной конкуренции и региональная интеграция.

В последней четверти XX в. развитые страны перешли от индустриальной стадии развития к стадии инновационной экономики. Большая часть ВВП в этих странах формируется в секторе услуг. В этих странах идет мощная концентрация интеллектуальных ресурсов и финансового капитала, а индустриальные производства постепенно переносятся в более отсталые в социальноэкономическом плане страны мира.

Несмотря на широкое употребление термина «глобализация», этот процесс изучен недостаточно. Глобализация - широкомасштабный всемирный процесс, охватывающий все стороны жизни, интегрирующий национальные социальноэкономические образования в единую мировую и общественную систему. Отличительной чертой глобализации является существенное переплетение ссудных капиталов, расширение объема кредитных ресурсов и возможности доступа к ним в любой точке мира. Для эффективного использования притока капиталов должны сформироваться соответствующие институты - отлаженные рынки финансовых инструментов, особенно государственных обязательств; законодательство о банкротстве; процедуры управления компаниямибанкротами; хозяйственное право в целом; защита прав собственности в патентной системе; правила хозяйственного учета; органы государственного регулирования для защиты интересов стран-участниц.

Глобальные процессы, происходящие в мировом хозяйстве, начиная с последней четверти прошедшего столетия, эволюционно создали общепланетарные контуры новой экономической системы. Эти процессы, постепенно охватившие все регионы и сектора мирового хозяйства, принципиально изменили соотношение между внешними и внутренними факторами развития национальных хозяйств в пользу первых. Ни одна страна оказалась не в состоянии рационально формировать и реализовывать экономическую политику, не учитывая приоритеты и нормы поведения основных участников мирохозяйственной дея- 
тельности. Международные хозяйственные связи превратились в важный инструмент эффективного распределения ресурсов и обеспечения экономического роста в глобальном масштабе.

Главной целью социально-экономического развития на среднесрочную перспективу является формирование такой модели национальной экономики, которая бы обладала долгосрочным потенциалом динамичного роста, способностью обеспечивать последовательное повышение благосостояния населения, эффективное воспроизводство, постоянную модернизацию производственного потенциала, оптимизацию управления, укрепление инновационной сферы и конкурентоспособности страны. Для этого должны быть сформированы соответствующие институциональные формы и механизмы.

Институционализация - это процесс, когда некая общественная потребность начинает осознаваться как общесоциальная, а не частная, и для ее реализации в обществе устанавливаются особые нормы поведения, готовятся кадры, выделяются ресурсы [1, с. 153].

Формирование социально ориентированной рыночной экономики в Республике Беларусь происходит в сложных условиях мирового экономического развития, которые характеризуются возрастанием экономических, политических, культурных и других противоречий между различными странами. Современное мировое хозяйство характеризуется разрастанием и усложнением системы институтов, вызванных к жизни непреходящими и сверхновыми потребностями. Что неизбежно обусловило процесс институционализации общемировых экономических отношений и взаимосвязей.

Процессу институционализации способствовало создание транснациональных корпораций как новых международных институтов глобализационного характера. Транснационализация - это межгосударственная интеграция, основанная на становлении и развитии в мировой экономике крупных транснациональных по масштабам своей деятельности компаний - транснациональных корпораций (ТНК) реального и финансового сектора. К ТНК относятся корпорации, имеющие дочерние фирмы в двух или более странах независимо от юридической формы или сферы деятельности и осуществляющие координацию их деятельности. В настоящее время в мире насчитывается 63 тыс. ТНК. Число ТНК за последние два десятилетия увеличилось более чем в 6 раз. Они контролируют $2 / 3$ всей мировой торговли и $80 \%$ иностранных инвестиций, на их долю приходится 80\% патентов и лицензий на новейшую технику и современные технологии [4, с. 4-5].

Процессы глобализации теснейшим образом связаны с институционализацией мирового хозяйства. В международных экономических отношениях, также как и в рамках национальных экономических систем отдельных стран, формируются определенные институты, формальные и неформальные нормы, правила, институциональные регуляторы, а также организационные структуры, осуществляющие институциональное регулирование и прогнозирование.

Институционализация мирохозяйственных связей представляет собой процесс определения и закрепления норм, правил, статусов, ролей и организацион- 
ных структур, приведение их в систему управления, которая способна действовать в направлении удовлетворения некоторой общественной потребности. Институционализация - это замена спонтанного и экспериментального поведения на предсказуемое поведение, которое ожидается, моделируется, регулируется в процессе институционального проектирования. В мирохозяйственных связях складываются и видоизменяются конкретные социальные институты, происходит институционализация международных экономических отношений.

Необходимость институционализации международных торговых отношений обусловлена следующими факторами:

- свободный обмен информацией и беспрепятственная торговля способствуют созданию институтов благодаря появлению спроса на их услуги, обеспечивающие деятельность рынка;

- $\quad$ взаимодействие с большим числом партнеров увеличивает спрос на услуги формальных институтов, обеспечивающих предоставление информации и условия выполнения заключенных контрактов;

- обмен информацией о новых технологиях, организационных и управленческих формах деятельности.

Переход экономики Беларуси в новое качественное состояние предопределяет значимость активизации инновационной деятельности, что в свою очередь требует институциональных изменений в структуре общественного производства, системе управления, образовании на основе знаний и информации. С учетом этого необходимо существенно преобразовать институциональные условия ведения бизнеса, сформировать благоприятный инновационный климат, осуществить прорыв в сфере использования современных информационных и коммуникационных технологий, как в области воспроизводства знаний, так и в отраслях, использующих нововведения.

Один из ключевых факторов повышения конкурентоспособности страны, развития в ее пределах эффективной НИС - государственное вмешательство. Государственная инновационная политика направлена на создание благоприятного экономического климата для осуществления инновационных процессов (в том числе и на уровне регионов) и является связующим звеном между академической наукой и производством;

Институциональные структуры, заложенные в основу НИС развитых стран, объединяет, прежде всего, наличие нескольких уровней организации и управления. Так, НИС Норвегии и Австралии состоит из шести уровней, Германии и Великобритании - из четырех, Бельгии, Швейцарии, Австрии - из трех. НИС развитых стран отличаются по своей направленности и роли государства, прежде всего, за счет ориентации на удовлетворение особых национальных приоритетов: Финляндия - диверсификация экономики, Франция - создание сети мелких технологических фирм, США - поддержка реструктуризации экономики.

Можно говорить о создании к настоящему времени глобальной научнотехнической и технологической среды, важными структурными элементами которой являются университеты и исследовательские сети. Становится очевид- 
ным, что ядро современной науки образуют сети ученых, научных институтов, организаций, лабораторий всех стран мира, вовлеченных в проведение совместных исследований и выполнение совместных научно-исследовательских проектов. Для повышения эффективности их взаимодействия необходимо целенаправленное формирование научной среды и научно-исследовательской инфраструктуры, ориентированной на сотрудничество - так называемой кооперативной научной среды. Формирование кооперативной научной среды предполагает использование особой системы распространения информации, которая позволит каждому участнику исследования получать доступ к нужным сведениям и тесно взаимодействовать с коллегами на протяжении всего периода совместной работы. Очевидно, что примером подобной системы могут послужить компьютерные сети, обеспечивающие пользователям доступ к информации по всему миру.

Основными элементами институциональной структуры инновационных отношений являются формальные (например, юридические, экономические, финансовые, образовательные) и неформальные институты, которые задают правила и диапазон возможностей для инноваций; накопленные знания и научно-технические учреждения, которые предоставляют образовательные услуги; каналы передачи знаний, навыков, информации, что в значительной степени определяется социальными и культурными характеристиками населения; динамические факторы внутри субъектов инновационных отношений или в их непосредственном окружении.

В Республике Беларусь формируется национальная инновационная система на основе сочетания исследовательской среды, производящей новые знания и информацию, конкурентной среды, реализующей инновации и институционального механизма их взаимодействия.

С учетом институционального аспекта национальную инновационную систему можно определить как совокупность государственных, региональных, частных и общественных институтов, регуляторов и механизмов их взаимодействия, которые организуют деятельность по созданию, хранению и распространению новых знаний и технологий, поддержки, использованию стимулов и льгот для инвестирования средств в осуществление инновационной деятельности, производству инновационных конкурентных товаров и услуг, их продвижения и реализации на рынке с целью обеспечения устойчивого экономического роста и реализации конкурентных преимуществ национальной экономики в системе глобальных общемировых взаимосвязей.

\section{ВЫВОДЫ}

Таким, образом, исходя из вышеизложенного приходим к следующим выводам.

1. Инновационное социально-экономическое развитие Беларуси требует разработки новой парадигмы восприятия общественного прогресса, который рождается одновременно с революционным приходом шестого технологического уклада. Основой такой парадигмы должна стать институциональная тео- 
рия, учитывающая, что воспроизводство новых знаний, в процессе которого участвуют наука, образование и экономика, является важнейшим системообразующим фактором социально-экономических преобразований.

2. Перед национальной экономикой и системой государственного управления сегодня стоит важная задача планирования необходимого объема и качества воспроизводства интеллектуальных ресурсов страны. Важнейшее значение в этом вопросе отводится фундаментальной науке. Там, где под контролем общества развивается фундаментальная наука, там последовательно осуществляются и востребованные экономикой прикладные исследования. Особая роль фундаментальной науки заключается в воспитании образованной нации как непременного условия самостоятельного и сильного гражданского общества.

3. Фундаментальная экономическая наука должна не только сохранить ведущие научные школы, но и обеспечить транспарентность своей деятельности, создав при этом новые условия для развития перспективных направлений исследований, прежде всего в области нанотехнологий, обеспечив экономический прорыв для Беларуси.

4. Особую актуальность приобретает формирование концептуальных направлений реализации институциональной стратегии как основы функционирования и инновационного развития национальной экономики в целях реализации концепции устойчивого экономического роста и повышения конкурентоспособности страны. Однако, несмотря на большое внимание к изучению данной проблематики, системных исследований в данном направлении до сих пор не существует - отсутствует разработанная методологическая основа институционального развития национальной инновационной системы, сохраняется проблема создания действенных институтов отечественной инновационной сферы в условиях глобализации.

5. Быстрое развитие «новой экономики», растущая взаимосвязь между рынками капитала и новыми технологиями, усиление социальной ориентации последних, масштабный характер создания и использования знаний, технологий, продуктов, услуг обусловили возникновение национальных инновационных систем как институциональной основы инновационного развития стран. Эти глубинные процессы создали те необходимые предпосылки, без которых было бы невозможно органичное соединение субъектов и объектов инновационной деятельности в единую целостную систему. К таким предпосылкам можно отнести единое информационное пространство, сетевые технологии, системный кадровый квалифицированный ресурс, единую экономическую и правовую среду, крупные проекты национального масштаба, интегрирующую роль государства, инновационную культуру общества.

6. В сфере корпоративного управления необходимо активизировать процесс интеграции промышленных предприятий с финансовым, инвестиционными и другими организациями транснациональные корпорации и межгосударственные финансово-промышленные группы, активное формирование которых произошло с развитием интеграции Российской Федерации и Республики Беларусь, должно способствовать восстановлению кооперационных связей и това- 
рооборота между ними и другими странами СНГ, ближнего и дальнего зарубежья.

7. Особенность современной хозяйственной системы - её динамичность. Если когда-то корпорации могли позволить себе составлять долгосрочные планы развития и старательно отслеживать насколько близок результат, то теперь они вынуждены иметь целый пакет возможных проектов, которые принимаются к реализации в зависимости от ситуации. Более того, если учесть, что довольно узкая группа лидеров крупных корпораций постоянно отслеживают стратегии друг друга и прямо или косвенно согласуют их, то новый тип корпоративного эффективного управления экономическими процессами можно сформулировать так: управлять сегодня надо не результатом и даже не решением, а процессом принятия решения. Очевидно, что институт глобальных альянсов и есть та форма, которая позволяет принимать участие в самом процессе принятия решений.

\section{ЛИТЕРАТУРА}

1. Дорина, Е.Б. Проблемы институционализации в контексте глобальной интеграции и трансформации мировой экономики / Е.Б. Дорина // Вестник экономической интеграции. - 2009. - №11-12. - С.152-162.

2. Дорина, Е.Б. Национальная инновационная система Беларуси: проблемы развития и пути их решения / Е. Дорина // «Посткризисное очертание инновационных процессов» материалы Х Друкеровских чтений / под ред. Нижегородцева Р.М., Москва - Новочеркасск: ЮРГТУ (НПИ), 2010. - С. 392-399.

3. Дорина, Е.Б. Институциональные меры по регулированию регионального развития / Е. Дорина // Сборник трудов института экономики и управления. - Выпуск X, Таллин, Институт экономики и управления, ECOMEN, 2010. - C.47-57.

4. Янсен, Ф. Эпоха инноваций / Ф.Янсин: Пер. с англ.- М.: ИНФРА, 2002.

5. Дорина, Е.Б. Инновационное развитие национальной экономики Беларуси: институциональные условия и принципы / Е. Дорина // Интеграция науки, образования и производства - стратегия развития инновационной экономики [Текст]: материалы I Междунар. науч.-практич. конф. (Екатеринбург, 2526 января 2011 г.) / [отв. за выпуск М.В. Федоров, Э.В. Пешина, В.П. Иваницкий]. Екатеринбург: Изд-во Урал. гос. экон. ун-та, 2011. Секция 1. Инновационная экономика: теория и практика. Ч. І. - С.79-82.

6. Дорина, Е.Б. Институциональная теория и решение проблем глобального развития экономики и управления / Белорусский экономический журнал. - 2010. - № 3. - С. 48-55.

7. Дорина, Е.Б. Инновационное развитие белорусской экономики: приоритеты и факторы достижения нового качества экономического роста / Е. Дорина // Управление инновациями - 2011 / Материалы межд. науч. прак. конф. 14-16 ноября 2011 г. / под ред. Р.М. Нижегородцева. - М. : ЛЕНАНД, 2011. - С. 72-77. 
8. Фуруботн, Э.Г. Институты и экономическая теория: Достижения новой институциональной экономической теории / Э.Г. Фуруботн, Р.Рихтер: Пер. с англ. под ред. В.С. Катькало, Н.П. Дроздовой. - СПб.: Издат. дом СанктПетерб. гос. ун-та, 2005.

9. Ожигина, В. Инновационная политика регионального интеграционного объединения / В. Ожигина // Журнал международного права и международных отношений - 2011- № 2 - С.85-90.

10. Молчанова, О.П. Формирование стратегических альянсов для реализации высокотехнологичных социально-ориентированных проектов: сравнительный анализ российского и зарубежного опыта / О.П. Молчанова, А.М. Шестоперов // Интеграл - 2012 - Том 2 - № 64 - С. 111-116.

11. Bellman L., Knowledge transfer and the integration of research, policy and practice / L. Bellman, J. Webster, A. Jeanes // Journal of research in nursing 2010 - № 16 - pp. 254 - 270. 